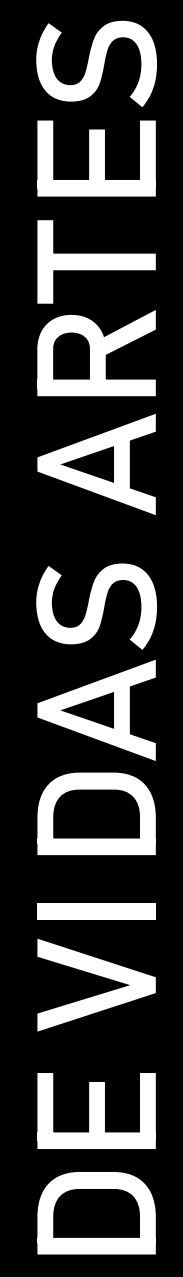

PAULA GUERRA E LÍGIA DABUL (EDS.) 


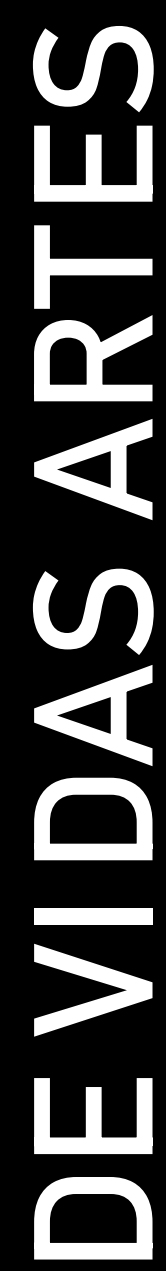

\section{PAULA GUERRA E LÍGIA DABUL (EDS.)}

Design por Irandina Afonso

Ilustração da Capa por Lua Celina

Publicado em Setembro 2019

Universidade do Porto. Faculdade de Letras

[University of Porto. Faculty of Arts and Humanities]

Porto, Portugal

ISBN 978-989-8969-18-7

Suporte: Eletrónico - Formato: PDF / PDF/A 


\title{
III.6. Mediações em Pequenas Vozes. práticas distintas no contato com a arte
}

\section{III.6. Mediations at Pequenas Vozes, distinct practices in}

\section{the contact with art}

\section{Clarisse Martins Monteiro}

\begin{abstract}
Resumo
Mediação é um termo que circula com bastante frequência no meio artístico e acadêmico brasileiros a partir de momentos difíceis de serem datados com precisão. No contexto do acelerado processo de democratização do acesso à arte vivido no país, estudos e práticas das ditas mediações em exposições de artes visuais, por exemplo, ganham cada vez mais legitimidade no mundo da arte. Contudo, empregado de forma contextualizada, o termo é atribuído a diferentes usos e definições. O presente trabalho tem como objetivo ampliar o entendimento sobre o conceito e contribuir para as discussões no campo da arte e sociologia da arte, através da análise do processo de educação em artes e da produção artística de jovens pertencentes às classes populares do Centro do Rio de Janeiro, participantes do projeto social Pequenas Vozes do Carmelo.
\end{abstract}

Palavras-chave: Arte, mediação, arte-educação, classes populares.

\begin{abstract}
Mediation is a term that has been widely used throughout the brazilian artistic and academic communities since times that can't be easily precised. In the context of the fast-paced process of democratization of the access to art that has been going on in Brazil, studies and practices of the so called mediations in visual arts exhibits, for example, have been gaining legitimacy in the art world. Nevertheless, when employed in context, the term is associated to different uses and definitions. The present work has the objective of amplifying the understanding of said concept and of contributing with the discussions in the fields of art and art sociology, through the analysis of the art education process and of the artistic production of youngsters pertaining to the low-income classes of Rio de Janeiro city's Centre, all of them participants of the social project Pequenas Vozes do Carmelo.
\end{abstract}

Key words: Art, mediation, art education, low-income class.

\section{Entrada}

Mediação é um termo frequentemente atribuído com muita naturalidade a práticas muito distintas, denotando essa naturalidade a necessidade de um debate aprofundado. Autores como Davallon (2003) e Almeida (2008), por exemplo, em estudos nas áreas das ciências da informação e da comunicação, chamam a atenção para um caráter "plástico" do termo (Almeida, 2008: 3), já que, empregado na maioria das vezes de forma 
contextualizada "estende suas fronteiras para dar conta de realidades muito diferentes entre si” (Davallon, 2003: 38). Assim, segundo Almeida (2008: 3), a ideia de mediação abarca:

\begin{abstract}
Desde as velhas concepções de "atendimento ao usuário", passando pela atividade de um agente cultural em uma dada instituição - museu, biblioteca, arquivo, centro cultural - até a construção de produtos destinados a introduzir o público num determinado universo de informações e vivências (arte, educação, ecologia, por exemplo), chegando à elaboração de políticas de capacitação ou de acesso às tecnologias de informação e comunicação, etc.
\end{abstract}

Da mesma forma, nas áreas da arte e da arte-educação, as ditas mediações costumam ser utilizadas em diversos momentos e por diversos atores sociais, dando conta das mais diversas ações. Em exposições de artes visuais, a figura do mediador - denominação que substitui o guia e o monitor - se faz cada vez mais presente, bem como a procura por visitas mediadas em lugar das visitas guiadas. Mas basta fazer algumas visitas a equipamentos culturais diferentes para perceber que nem mesmo à figura do mediador em exposição é atribuído o mesmo conjunto de funções.

Mas afinal o que se entende por mediação? Qual relação estabelece com a função de mediador? Quais são suas implicações teóricas, técnicas, culturais, sociais, econômicas e políticas? O presente trabalho tem por objetivo refletir sobre alguns usos do termo a partir de uma breve apresentação e análise de um estudo de campo ${ }^{180}$ sobre as atividades artísticas desenvolvidas no Pequenas Vozes do Carmelo, um projeto social situado no centro da cidade do Rio de Janeiro. Que práticas, atores sociais envolvidos, espaços e tempos substancialmente diferentes são entendidos como mediação? Contudo, antes de partir para a descrição e análise das atividades do projeto, contextualizo brevemente a acepção mais amplamente difundida do termo, qual seja a empregada para designar o conjunto de práticas em ações educativas em exposições de artes visuais.

\title{
2. As mediações nos processos de democratização do acesso à cultura e da democracia cultural
}

No meio artístico e acadêmico brasileiros, a partir de momentos difíceis de serem datados com precisão, o termo mediação circula com bastante frequência. Contudo, a intensificação desta circulação aumenta com a

\footnotetext{
${ }^{180}$ Resulta do desenvolvimento da pesquisa de mestrado intitulada "Tão perto e tão distante: arte, mediação e o significado de praticas sociais para as classes populares do Centro do Rio de Janeiro", vinculada ao Programa de Pós-Graduação em Estudos Contemporâneos das Artes (da Universidade Federal Fluminense, na linha de Estudos das Artes em Contextos Sociais sob orientação científica da Professora Doutora Lígia Dabul.
} 
abertura de centros culturais em diversos países - ainda nos anos 1970 - de fundações culturais ligadas à iniciativa privada - ainda na década 1990 - no Brasil - e consequentemente com o aumento da oferta de eventos culturais e, mais fortemente, a partir da década 2000, com o crescente processo de democratização vivido no país. As políticas de governo implementadas com a chegada de Luiz Inácio Lula da Silva à Presidência da República (20032011) criaram condições para que o Brasil, entre outras coisas, ganhasse destaque internacional no mundo da arte. Desde 2011, o Centro Cultural Banco do Brasil do Rio de Janeiro, por exemplo, passa a figurar nas primeiras posições do ranking das 20 exposições de artes visuais mais visitadas por ano ${ }^{181}$ promovido pela revista inglesa The Art Newspaper, considerada uma das principais fontes internacionais de informação sobre arte ${ }^{182}$.

Com o objetivo de conduzir um público massivo e diversificado, composto em grande parte por "leigos", pelos salões de exposição, o recurso às visitas mediadas passa a ser adotado como instrumento para "viabilizar", "facilitar" ou "qualificar" seu encontro com uma arte, antes restrita a poucos (Muniagurria, 2006). Recurso, este, responsável por ativar o que Bourdieu (1983, 2015[1979]) chama de disposição estética, ou seja, fazer com que tais indivíduos adquiram a competência para reconhecer como artísticos os objetos de arte exibidos nos equipamentos e valorizados no mundo da arte. Nesse contexto, a formação de mediadores e de ações educativas em museus e centros culturais passa a ser legitimada pelo aval de especialistas tanto do mundo da arte quanto da educação (museólogos, artistas, curadores e arte-educadores).

As ditas mediações provém, então, do ideal de igualdade de acesso de todos à cultura - reivindicação inatacável em regime democrático -, ou seja, visam o acesso de todos ao consumo de um bem tido como universal. Entretanto, um acesso organizado pelos poderes públicos e instituições culturais que, com sua produção e organização simbólicas, instituem uma ordem social (Fleury, 2009), revelando, pois, as dimensões sociopolítica e econômica implicadas na prática. O ideal de democratização do acesso à cultura encontra seu contraponto na ideia da democracia cultural. Enquanto

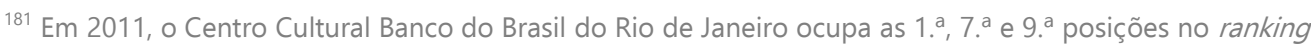
das vinte exposições mais visitadas do ano. Em 2012, a instituição ocupa as 2. ${ }^{a}, 7$. $^{a}$ e 11. ${ }^{a}$ posições. Em 2013,

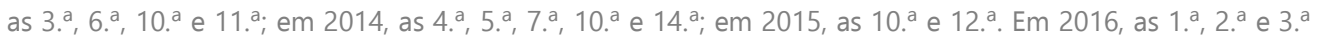
posições. Em 2017, o CCBB Rio ocupa a 6. posição geral no ranking.

182 O levantamento de dados para a revista é feito pelo Instituto Brasileiro de Museus (Ibram/MinC) fundado em 2009 pelo então presidente Lula - através do projeto Exposições no Brasil, criado em 2010.
} 
aquela visa reduzir as desigualdades de acesso à "alta cultura", à arte legitimada e "tem como finalidade eliminar os obstáculos à frequentação das obras do patrimônio cultural e da criação contemporânea"; a democracia cultural cria uma estratégia política alternativa focada no "'desenvolvimento cultural' consciente das identidades locais ou regionais, das culturas minoritárias e das tradições populares." (Coulangeon, 2014: 24-25).

Nas práticas de mediação em exposições, contudo, é possível perceber também a presença deste ideal, já que, segundo Muniagurria (2006), na formação de mediadores para ações educativas em exposições de arte contemporânea, existe a utilização de técnicas que limitam a imposição de leituras preestabelecidas das obras, estimulando as produções de sentido pelos diferentes visitantes. Atuando também na tensão entre essas duas perspectivas encontra-se o Pequenas Vozes do Carmelo ${ }^{183}$, um projeto sem fins lucrativos, situado no bairro da Lapa, região central do Rio de Janeiro, que presta assistência social através da educação em artes em diferentes linguagens e que valoriza tanto o contato com o capital cultural legitimado quanto os saberes e as experiências dos participantes.

\section{Pequenas Vozes: mediações em contexto}

Fundado em 2009, o projeto social tem como idealizadora e mantenedora uma instituição católica, a Província Carmelitana de Santo Elias, embora não se configure como um projeto religioso. Lá são oferecidas oficinas de teatro, flauta doce, percussão, violão e canto coral para crianças e adolescentes dos seis aos 17 anos, em situação de vulnerabilidade social ${ }^{184}$, com renda familiar de até três salários mínimos ${ }^{185}$, moradores do bairro da Lapa e entorno. As aulas têm uma ou duas horas de duração e acontecem no período noturno (18h às 20h), em encontros semanais com turmas infantis (seis aos 11 anos) e de adolescentes (12 aos 17 anos). A equipe de profissionais é composta por uma assistente social, uma pedagoga e cinco professores, com formação superior e experiência com arte-educação em projetos sociais. Enquanto aquelas se dedicam aos atendimentos de serviços sociais, estes se dedicam ao ensino de linguagens artísticas, vendo na educação artística, além de

\footnotetext{
183 Para mais detalhes, consultar https://www.facebook.com/projetosocialpequenasvozesdocarmelo/.

184 Segundo Monteiro (2011), a formulação do conceito de vulnerabilidade social ainda é amplamente debatida,principalmente na área de assistência social, visto que são múltiplos seus condicionantes. Aqui o termo é compreendido como a exposição dos indivíduos a riscos de diferentes naturezas (econômicos, culturais e/ou sociais), que os impedem de satisfazer necessidades básicas.

${ }^{185}$ Valor do Salário mínimo brasileiro em 2019: R\$ 998.
} 
benefício para o desenvolvimento pessoal dos alunos, uma oportunidade de profissionalização e sustento financeiro.

O direcionamento das atividades é determinado, geralmente, da seguinte maneira: no início de cada ano, a equipe se reúne e debate a escolha de um tema que será o fio condutor dos trabalhados ao longo das oficinas. Os critérios para essa escolha são, primordialmente: estar relacionado às culturas brasileiras e se relacionar, de alguma forma, com o universo das famílias participantes. Uma vez escolhido ele é trabalhado em cada oficina paralelamente. Nesses encontros, os professores desenvolvem também o trabalho para a formação técnica referente à linguagem artísticas que dominam, sempre em diálogo com os saberes e a realidade dos alunos.

Nesses encontros em sala de aula, os professores sondam os alunos para mapear o que pensam ou sabem em relação aos temas ou a quaisquer outros assuntos que perpassem os encontros; estabelecem o diálogo a partir do tema ou material artístico usado como referência (vídeos, obras de arte, peças teatrais, exposições, cenas, músicas, etc.); conduzem as discussões e a produção artística dos participantes, equilibrando falas do grupo e intervenções do próprio professor - às vezes o professor lançando as ideias, outras, ele retomando falas do grupo; discutem os temas ou obras relacionando-os com o cotidiano do grupo, e promovem que ele construa sua própria interpretação sobre eles; e, também, dão a conhecer algumas das regras frequentemente presentes em ambientes de apresentação artística (exposições, concertos, apresentações teatrais, etc.).

Muniagurria (2006: 4), ao tratar da formação de mediadores para exposições de artes visuais, destaca técnicas extremamente similares e frequentemente prescritas para mediações desse tipo, validadas por especialistas. Técnicas que, como vimos anteriormente, estimulam a livre interpretação e criação de sentido pelos mais diversos públicos, sem impor códigos identificados com determinados segmentos sociais, ou seja, técnicas que, buscam uma certa democracia cultural, inspiradas na ideia freireana de educação. Tal inspiração pode ser identificada pela quebra de hierarquia entre a figura do mediador e do público observada nessa prática, em que o conhecimento de todos são considerados. Paulo Freire (2017[1968]: 82), ao tratar da quebra hierárquica em sala de aula, diz que "a razão de ser da educação libertadora está no seu impulso inicial conciliador" que supera a contradição "educador-educandos, de tal maneira que se façam ambos, 
simultaneamente, educadores e educandos". Davallon (2003), por sua vez, destaca um dos usos comuns atribuídos à mediação que, pressupondo um conflito, se apoia na conciliação. Desse modo, poderíamos dizer que existe uma mediação não só nessas ações em exposições e nas oficinas do projeto, mas no próprio cerne da educação libertadora de Paulo Freire, em que educador-educando e educando-educador se conciliam através do diálogo e da quebra da hierarquia frequentemente estabelecida entre eles.

Além das atividades desenvolvidas em sala de aula, a equipe de profissionais, atenta à oferta de eventos culturais na cidade ao longo do ano, costuma, promover passeios culturais, como ida a exposições, apresentações teatrais, shows, concertos etc., escolhidos por sua relevância e diálogo com os temas e linguagens artísticas trabalhados. Tal prática, também chamada de mediação, juntamente às técnicas descritas anteriormente, se aproximam da definição de mediação cultural feita por Coelho (1997: 247):

Processos de diferente natureza cuja meta é promover a aproximação entre indivíduos ou coletividades e obras de cultura e arte. Essa aproximação é feita com o objetivo de facilitar a compreensão da obra, seu conhecimento sensível e intelectual - com o que se desenvolvem apreciadores ou espectadores, na busca de formação de públicos para a cultura ou de iniciar esses indivíduos e coletividades na prática efetiva de uma determinada atividade cultural.

Definição, esta, que transita mais frequentemente no mundo da arte. Neste contexto, as competências do professor são entendidas como as do mediador, que, mais do que mobilizar os saberes, precisa envolver a capacidade educativa e cultural de utilizar esses saberes: "Trata-se de saber onde está a informação, como buscá-la, transformá-la em conhecimento específico para fazer aquilo que se quer fazer" (Almeida, 2008: 20).

Além disso, nos momentos de realização desses passeios culturais, os professores do projeto também dialogam com os mediadores das instituições, fornecendo dados e informações sobre o grupo, resgatando referências de experiências dos alunos em sala de aula e fazendo intervenções pontuais. Percebe-se, deste modo, que os professores mediam o próprio encontro dos mediadores das instituições com os alunos: "facilitam", para aqueles, a identificação e o reconhecimento do grupo, possibilitando escolhas técnicas mais efetivas para cumprirem o objetivo de "viabilizar" o encontro do público com a arte; para estes, possibilitam que reflitam, ressignifiquem e remodelem experiências pregressas, contribuindo para o desenvolvimento da percepção estética. 
O encerramento anual das atividades no Pequenas Vozes do Carmelo é marcado pela apresentação de um espetáculo musical construído coletivamente, com participação total dos alunos. Nas oficinas de teatro, as cenas surgem de exercícios de improvisação teatral a partir de pesquisas e debates sobre o tema, de experiências vividas pelos jovens fora do ambiente do projeto - que se relacionem diretamente com o tema ou não - e das experiências vividas durante os passeios culturais.

A possibilidade de recorrer ao material de outras experiências e expressar esse material através da linguagem e criação cênica, gera a possibilidade de criar novas modalidades de experiência e de comunicação através da expressão, da linguagem artística (Dewey, 2010). Levando-se em consideração que muitos jovens participantes têm dificuldade com a leitura, escrita e oralidade, é possível perceber que, ao conseguirem dar corpo e definição às suas próprias experiências - tanto para eles mesmos quanto para os que os escutam, sejam os professores e colegas em aulas e ensaios, seja o público nas apresentações finais - conseguem se disponibilizar mais para as atividades e passam a ficar mais atentos às suas experiências, corroborando no desenvolvimento de suas percepções estéticas. Sendo assim, a própria linguagem, enquanto meio para uma comunicação efetiva, torna-se uma forma de mediação.

Cerca de dois meses antes da apresentação do espetáculo, há um esforço coletivo de ordenar e encadear de forma lógica - e emocionalmente intuída - o material cênico resultante do processo, excluindo e/ou criando novas cenas, se necessário. A dramaturgia é construída, ainda, de acordo com as canções trabalhadas nas oficinas de música e escolhidas durante 0 ano em comum acordo entre os professores, atendendo às necessidades de estarem adequadas ao nível técnico de execução dos alunos e estarem em consonância com as cenas criadas e com o nível de discussão teórica sobre o tema nas oficinas. Situações mediadas pelo diálogo.

Duas semanas antes da apresentação do espetáculo musical, acontecem os ensaios coletivos. Neles, todos os alunos e professores vão ao projeto todos os dias úteis da semana e todos os participantes de todas as oficinas ficam juntos, no mesmo espaço físico, construindo de fato o espetáculo, ou seja, juntando todas as partes que foram ensaiadas separadamente nas oficinas. Os musicais, compostos por aproximadamente oito canções intercaladas por cenas que conduzem uma linha dramatúrgica, 
possuem cerca de uma hora de duração e reúnem no palco, ao mesmo tempo, todos os alunos do projeto, que tocam, cantam e atuam, utilizando cenários, figurinos e adereços elaborados por eles a partir da temática central.

As apresentações, durante o período de observação (2013 a 2018) ${ }^{186}$, acontecem em uma única exibição e, desde 2015 são feitas em equipamentos culturais do Centro do Rio de Janeiro, através de parcerias e concessões feitas pelos gestores dos espaços ${ }^{187}$. Entre montagem, apresentação do espetáculo propriamente dito e desmontagem, os jovens e a equipe de profissionais permanecem por cerca de cinco horas nas dependências das instituições parceiras, ocupando os palcos, camarins, corredores e plateias, se maquiando, trocando os figurinos, afinando os instrumentos, se aquecendo, comendo e compartilhando as emoções e sentimentos envolvidos nessa preparação.

A apresentação nos equipamentos culturais - que institucionalizam uma ordem social através da legitimação de uma arte - é uma prática que também pode ser encarada como mediação. Embora as famílias participantes do projeto residam no Centro da cidade e, embora não haja obstáculos concretos para a visitação a esses espaços - muitos têm gratuidade de ingresso, o deslocamento até os espaços pode ser feito a pé, o projeto muitas vezes, distribui ingressos para eventos etc. - elas não costumam frequentálos. Bourdieu e Darbel (2003[1969]) já apontavam, em seus estudos sobre os públicos e a frequentação aos museus de arte da Europa na década de 1960, que os obstáculos à visitação são, antes de tudo, simbólicos.

Tal prática pode, portanto, ser considerada mediadora na medida em que opera uma conciliação da relação previamente estabelecida com esses espaços. Se antes esta população não os frequentava devido às barreiras simbólicas existentes, agora as barreiras se diluem a partir de uma apropriação desses lugares. Apropriação que é feita através do exercício de práticas sociais fundamentais para a população, como brincar, conversar, comer. Lígia Dabul (2008a, 2008b, 2009), ao tratar dos fatores que conformam a atribuição de sentido a uma obra de arte no contato com ela, já

\footnotetext{
${ }^{186} \mathrm{O}$ trabalho de campo se deu principalmente por observação participante durante o período em que atuei como professora da oficina de teatro e, sobretudo, no período em que se desenvolveu a pesquisa de mestrado, a partir de 2017.

187 Os alunos do Pequenas Vozes do Carmelo já subiram nos palcos da Sala Cecília Meireles / Espaço Guiomar Novaes (2015), Teatro João Caetano (2016), Salão Mário Tavares / Theatro Municipal (2017) e Centro Cultural da Light (2018).
} 
chamava atenção para as ações sociais concretas do público, para o que os atores sociais efetivamente fazem no contato com a arte.

Partir das ações sociais dos jovens nos espaços culturais nas horas em que os ocupam para as apresentações torna evidente o fato de que as barreiras à frequentação não estão relacionadas exclusivamente aos equipamentos culturais em si, à sua arquitetura, mas a tudo que os conforma, como as artes neles expostas, seus habituais frequentadores, funcionários e até mesmo sua localização dentro da própria região da cidade.

José Magnani (2002: 14) nos ajuda a pensar pelo viés da cidade como elemento que medeia a relação entre esse público e arte ao afirmar que, da mesma forma como não podemos pensar a arte sem levar em consideração os atores sociais, não podemos pensar a cidade como uma "entidade à parte de seus moradores", já que são "os moradores propriamente ditos, que, em suas múltiplas redes, formas de sociabilidade, estilos de vida, deslocamentos, conflitos, etc., constituem o elemento que em definitivo dá vida à metrópole." (2002: 15). O autor, ao longo de seus estudos (1998[1984], 1992, 2002) institui, então, as categorias "pedaço", "mancha", "trajeto", "pórtico" e "circuito"188 para entender a cidade nessa dinâmica de interação com os atores sociais. Tomando como referências essas categorias, é possível pensar de que maneira a população em questão se relaciona com a arte institucionalizada a partir do espaço urbano.

Embora a região do Centro do Rio seja considerada uma "mancha" cultural pelas categorias de Magnani, por possuir a maior oferta de equipamentos culturais da cidade ${ }^{189}$, essa oferta não é suficiente para

\footnotetext{
${ }^{188}$ Segundo o autor, essas categorias podem ser definidas da seguinte maneira: o "pedaço" é formado pelo compartilhamento de códigos ou pelo reconhecimento de códigos compartilhados por atores sociais de uma determinada rede de relações; a "mancha" é uma área contígua do espaço urbano dotadas de equipamentos que marcam seus limites e viabilizam uma atividade ou prática predominante; o "trajeto" se aplica a fluxos recorrentes no espaço mais abrangente da cidade e no interior das manchas urbanas, ligando equipamentos, pontos, manchas e permite pensar tanto uma possibilidade de escolhas no interior das manchas como a abertura dessas manchas e pedaços em direção a outros pontos no espaço urbano e, por consequência, a outras lógicas; os "pórticos" são espaços, marcos e vazios na paisagem urbana que configuram passagens que não pertencem a nenhuma mancha, ou seja, lugares fronteiriços; por fim, "circuito" é uma categoria que descreve o exercício de uma prática ou a oferta de determinado serviço por meio de estabelecimentos, equipamentos e espaços que não mantêm entre si uma relação de contiguidade espacial, sendo reconhecido em seu conjunto pelos usuários habituais.

${ }^{189}$ Museu do Amanhã, Museu de Arte do Rio, Museu Nacional de Belas Artes, Museu Histórico Nacional, Museu de Arte Moderna, Casa França-Brasil, Centro Cultural Paço Imperial, Conjunto Cultural da Caixa, Centro Cultural da Justiça Federal, Centro Cultural dos Correios, Centro Cultural Banco do Brasil, Centro Cultural da Light, Centro Municipal de Arte Hélio Oiticica, Theatro Municipal, Teatro SESI, Teatro SESC Ginástico, Teatro Dulcina, Teatro Nelson Rodrigues, Teatro Carlos Gomes, Teatro João Caetano, Teatro Glauce Rocha, Teatro Serrador, Teatro Riachuelo, Sala Cecília Meireles, Circo Voador, Fundição Progresso, Biblioteca Nacional, Real Gabinete Português de Leitura, Cinema Odeon, entre outros, são alguns exemplos de equipamentos culturais que podem ser encontrados na região.
} 
estabelecer a frequentação para este grupo de pessoas, habitantes dessa "mancha". A violência, por exemplo, é um fator que aparece em primeiro lugar no discurso de adolescentes e pais para justificar a não circulação pela região, a não ser por necessidade, como se deslocar para os locais de trabalho, por exemplo. Para esta comunidade, o contato com a arte, visto como sinônimo de cidadania, é bastante valorizado, mas não necessário à sobrevivência. Todos evitam sair à rua, principalmente no centro, porque, para eles, é muito perigoso e identificam ruas mais ou menos perigosas pelas quais precisam passar para o acesso aos equipamentos culturais. Seria a violência urbana a qual as pessoas estão submetidas um fator de mediação no contato com a arte?

Portanto, quando esses equipamentos culturais sediam as apresentações dos espetáculos musicais do projeto, cria-se a necessidade de que os participantes se desloquem até eles, operando, como foi dito, na conciliação da relação entre essas pessoas e espaços, ou seja, mediam essa relação. Até aqui foram descritas e analisadas as práticas educativas no Pequenas Vozes do Carmelo. Dizem respeito a uma ampla gama de atividades que envolvem diferentes espaços, tempos, atores, práticas e relações sociais, todas elas chamadas, também, de mediação.

\section{Mediação: outros usos e definições}

Existem ainda outros usos para as chamadas mediações que não foram abordados até agora, mas que merecem ser considerados. Nathalie Heinich (2014), por exemplo, ao traçar os novos paradigmas da arte contemporânea ${ }^{190}$ e as "condições materiais, sociais, jurídicas e axiológicas sob as quais determinados objetos podem ser considerados obras de arte" (Heinich, 2014: 373), verifica a presença e a necessidade cada vez maior de mediações como características dessa categoria.

Contudo, considera como mediação e mediadores os processos e atores sociais envolvidos na própria produção e legitimação da obra de arte. Na medida em que uma obra de arte contemporânea rompe com os cânones das artes clássica e moderna, utilizando, por exemplo, materiais cotidianos, o discurso sobre ela passa a ser necessário, contrariando a afirmação de senso comum sobre sua suposta "vacuidade" de sentido. A intelectualização das operações de produção acaba por determinar que:

\footnotetext{
190 Entendendo o termo "contemporâneo" não como uma categoria meramente cronológica da história das artes visuais, mas como um novo paradigma artístico, com características particulares.
} 
Uma obra de arte contemporânea quase nunca existe sem um texto, assinado ou não, escrito pelo próprio artista ou, melhor ainda, por um especialista - por um crítico ou curador. Exatamente da mesma forma como o contexto se tornou parte da obra, o discurso sobre a obra se tornou parte da proposta artística (Heinich, 2014: 379).

Sendo assim, para que a obra ultrapasse a fronteira entre o mundo ordinário e o mundo da arte, há uma exigência e um número, cada vez maiores, de mediações para que estas se estabeleçam no mundo da arte. Mais do que a mão do artista, é necessária a criação de um sistema externo à obra para que a autoria seja validada. Desta forma, a mediação se faz necessária como parte de um sistema exterior à obra que permite identificála como obra de arte, validar sua autoria, controlar sua reprodução e estabelecer seu valor de mercado. Ou seja, ela deixa de ser necessária apenas para a veiculação do sentido da obra. Dentro desse sistema atuam como mediadores os críticos, os próprios artistas, colecionadores, curadores, donos de galerias, peritos, historiadores etc.

Esse sistema exterior é explicado também por Marta Buskirk (2003) a partir da obra de Robert Morris, intitulada "Statement of Aesthetic Withdrawal". A autora evidencia o tensionamento dessa questão ao discorrer sobre a atribuição e/ou retirada do sentido estético-artístico da obra através de uma declaração (statement). O statement, segundo ela, pode ser considerado como uma forma de mediação por ser o ato que imbui a obra de sentido artístico. Seria uma mediação constitutiva, existente pelo menos desde os ready mades de Duchamp.

Como é possível observar, devido ao fato de não envolver o público ou espectador de uma obra, o conceito de mediação agora empregado, rasgando as fronteiras do entendimento até então abordados neste trabalho, inaugurando outras perspectivas. Heinich (2014), considera, ainda, outras formas das ditas mediações para além dos atores sociais envolvidos na criação e validação das obras de artes contemporânea. Para a autora, além dos objetos, instituições e discursos, qualquer palavra, imagem, número, as paredes das galerias, encartes etc. podem ser considerados como mediação. Segundo Heinich, "os critérios artísticos implícitos compartilhados por pessoas num contexto determinado são, portanto, mediações fundamentais, apesar de serem quase imperceptíveis - a não ser que sejam especificamente investigados." (Heinich, 2014: 379).

Seria algo equivalente ao que Almeida (2008: 12) chama de "interações quase mediadas", ou seja, relações que as pessoas estabelecem 
com os conteúdos dos meios, com os dispositivos técnicos utilizados. Estes, antes de servirem como instrumento para educar ou ensinar um capital cultural, informam sobre esse capital por carregarem em sua própria execução uma ação legitimada pelo aval de especialistas. O caráter mediador de dispositivos técnicos, no entanto, traz à tona uma dimensão política e econômica destacadas por Davallon (2003) ao tratar mais precisamente da mediação pedagógica, mas que está relacionado, em certa medida, com os espaços expositivos de artes visuais. Segundo o autor, na mediação pedagógica, a posição do educador como mediador envolve uma regulação das interações educacionais para que a relação aluno-conhecimento seja efetiva e conduza a um aprendizado. Para isso, há a utilização de dispositivos técnicos.

Davallon, então, questiona se esses dispositivos exercem também a posição de mediadores. Estaria, para ele, neste questionamento a dimensão política e econômica implícitas, pois se entendidas enquanto tal, pode-se aventar a possibilidade de se tornarem objetos de industrialização, por exemplo (Davallon, 2003: 41), o que traria implicações, no momento, não mensuradas.

O compartilhamento de critérios implícitos, em contexto determinado, como uma mediação quase imperceptível também pode ser observado em algumas ideias de Paulo Freire. Embora seus estudos sejam de grande relevância nas práticas em arte-educação - que, como vimos, são denominadas de mediação - Freire diz que o educador não ensina: "ninguém educa ninguém, ninguém educa a si mesmo, os homens se educam entre si, mediatizados pelo mundo" (Freire, 2017[1968]: 95). Para ele, o educadoreducando e educando-educador são, pois, mediatizados ${ }^{191}$ pelo objeto cognoscível, pela realidade e pelo mundo. Segundo o autor:

O objeto cognoscível, em lugar de ser o término do ato cognoscente de um sujeito, é o mediatizador de sujeitos cognoscentes, educador de um lado, educandos de outro, a educação problematizadora coloca, desde logo, a exigência da superação da contradição educador-educandos. (Freire, 2017[1968]: 94).

Freire considera, então, o próprio objeto do conhecimento como mediador de um trabalho educativo. Não esqueçamos, no entanto, que como vimos, essa educação problematizadora também pode ser entendida como mediação na medida em que supera a contradição educador-educandos ou,

\footnotetext{
${ }^{191}$ Freire muitas vezes utiliza a palavra mediatizar/mediatização/mediatizador e mediar/mediação/mediador em frases bastantes semelhantes, ou seja, trata-se de uma mesma ideia, com o mesmo significado, mas grafada de maneiras distintas.
} 
como dissemos, os concilia através da quebra da hierarquia comumente estabelecida entre eles. Freire diz, ainda, que essa conciliação é feita somente no momento em que o pensar do educador ganha autenticidade na autenticidade do pensar dos educandos, "mediatizados ambos pela realidade, portanto, na intercomunicação. Por isto, o pensar daquele não pode ser um pensar para estes nem a estes imposto." (Freire, 2017[1968]: 89).

Por fim, apresento mais um dos usos contextualizados do termo. John Dewey, em Arte como experiência, (2010[1934]: 358), ao tratar da substância comum das artes, diz que o "veículo é um mediador", um "meio", "um intermediário entre o artista e aquele que percebe." O autor identifica, ainda, dois tipos desses veículos mediadores, "coisas mediais intervenientes, através das quais algo remoto é levado a correr": "um externo àquilo que é obtido" e outro que é "absorvido nas consequências produzidas e permanece imanentes nelas". (Dewey, 2010[1934]: 354).

Por essas definições entende-se que um tipo está relacionado a algo que se faz para alcançar um objetivo e que poderia ser substituído por qualquer outra coisa, ou até mesmo eliminado. O outro, está relacionado, não ao fim, mas ao próprio processo que resulta em algo e que faz parte do resultado. Pensando na experiência artística, ao falar em veículo como mediador, o autor entende o termo de acordo com o segundo tipo, ou seja, como os meios incorporados aos resultados, como, por exemplo, os tijolos e argamassa de uma construção. No palco, ainda segundo o autor, os veículos são os atores, com suas vozes e gestos. Deste modo, podemos deduzir que os atores, ou os jovens do Pequenas Vozes do Carmelo, por exemplo, com seus corpos e suas experiências pregressas (material) através de suas vozes e gestos (veículos) são eles mesmos os intermediários de seu próprio mundo particular e individual com o mundo externo, ou seja mediadores de si.

\section{Considerações finais}

No presente trabalho, procurei identificar práticas atribuídas ao termo mediação, exercidas no mundo da arte e da arte-educação. A partir da descrição das atividades desenvolvidas em períodos anuais no projeto social Pequenas Vozes do Carmelo, foi possível observar como o termo, de forma muito natural, é utilizado para práticas substancialmente diferentes. As ditas mediações em exposições de artes visuais - as executadas pelos mediadores com o objetivo de incentivar a produção de sentido pelo público e "viabilizar", 
em certa medida, seu contato com as obras de arte - constituem apenas uma, e talvez a mais difundida, acepção do termo.

A partir dessa primeira definição, traçei a forma como o conceito passou a estar mais presente nas discussões dos ambientes artístico e acadêmico brasileiros. Foi possível, então, situá-la sócio, política e culturalmente nas discussões sobre democratização do acesso à arte e democracia cultural, principalmente após o período de crescente processo de democratização vivido no país. Se as mediações, entendidas como as ações educativas em espaços onde uma determinada arte é apresentada, participam da produção de sentido atribuída a uma obra por diversos públicos, outras práticas e técnicas também o fazem. Como disposto ao longo deste capítulo, vários são os fatores envolvidos no contato de diferentes públicos com as artes e com os espaços em que são apresentadas, fatores que ultrapassam os limites da estrita relação espectador/obra ou espectador/mediador/obra, mas que, ainda assim, poderiam ser considerados como mediadores.

No caso dos aspectos envolvidos no processo de educação em artes desenvolvido no Pequenas Vozes, foi possível observar alguns desses fatores, como, por exemplo, a duração da permanência nos espaços de apresentação, a qualidade desta permanência através das ações sociais praticadas pelos atores envolvidos, o deslocamento pela cidade até os equipamentos culturais, a relação que se estabelece com a cidade, as relações construídas por esses atores no cotidiano (alunos e professores e os próprios alunos entre si), as experiências vividas e remodeladas dos participantes, etc.

Além disso, chamou-se atenção, ainda, para outros tipos de mediação fundamentais: aqueles cujos critérios artísticos estão implícitos, como os que atuam na criação de sentido e na própria validação de uma obra, estabelecendo-a enquanto tal no mundo da arte; e os próprios atores sociais como mediadores entre seus mundos particulares e o mundo exterior no desenvolvimento de suas percepções estéticas. Intuiu-se lançar luz sobre os diferentes aspectos a serem levados em consideração no campo das discussões sobre mediação em arte. Acredita-se que a articulação desses aspectos propicie um possível avanço na conscientização de suas implicações teóricas, técnicas, culturais, sociais, econômicas e políticas, contribuindo não só para os estudos sobre os públicos da arte, mas para a 
área de atuação da categoria de mediadores, cada vez mais presente no mundo da arte.

\section{Referências Bibliográficas}

Almeida, M. A. (2008). Mediação cultural na sociedade da informação: considerações sócio-culturais e políticas em torno de um conceito [online]. Comunicação apresentada no 32. ${ }^{\circ}$ Encontro Anual da Anpocs. Caxambu: ANPOCS. Acedido em: https://www.anpocs.com/index.php/papers-32-encontro/gt-27/gt10-21/2381marcoalmeida-mediacao/file

Bourdieu, P., \& Darbel, A. (2003[1969]). O amor pela arte: os museus de arte na Europa e seu público. São Paulo: Editora Zouk.

Bourdieu, P. (2015[1979]) A Distinção. Crítica social do julgamento. Porto Alegre: Editora Zouk.

Bourdieu, P. (1983) Gostos de classe e estilos de vida. In Ortiz, R. (Org.). Pierre Bourdieu: Sociologia (pp. 82-121). São Paulo: Editora Ática.

Buskirk, M. (2003). The contingent object of contemporary art. Cambridge, Massachusetts: The MIT Press.

Coelho, T. (1997). Dicionário crítico de política cultural. São Paulo: Iluminuras.

Coulangeon, P. (2014). Sociologia das práticas culturais. São Paulo: Edições SESC São Paulo.

Dabul, L. (2008a). Conversas em exposição: sentidos da arte no contato com ela. Arte \& Ensaios, 16, pp. 54-63.

Dabul, L. (2008b). Museus de grandes novidades: centros culturais e seu público [online]. Horizontes Antropológicos, 29(14), pp. 257-278.

Dabul, L. (2009). Arte em observação. Revista Poiésis, 14, pp. 216-243.

Davallon, J. (2003). La médiation: la communication en procès? MEI: Médias et Information, 19 (Médiations \& Médiateurs) (pp. 37-59). Psris: UFR Communication de I Université Paris 8.

Dewey, J. (2010). Arte como experiência. São Paulo: Martins Fontes - selo Martins.

Fleury, L. (2009). Sociologia da cultura e das práticas culturais. São Paulo: Ed. SENAC São Paulo.

Freire, P. (2017[1968]). Pedagogia do oprimido. Rio de Janeiro/São Paulo: Paz e Terra.

Heinich, N. (2014). Práticas da arte contemporânea: Uma abordagem pragmática a um novo paradigma artístico. Sociologia \& Antropologia, 4(2), pp. 373-387.

Magnani, J. G. (1992). Da periferia ao centro: pedaços \& trajetos. Revista de Antropologia, 35, pp. 191-203. 
Magnani, J. G. (2002). De perto e de dentro: notas para uma etnografia urbana. Revista Brasileira de Ciências Sociais, 49, pp.11-29.

Magnani, J. G. (1998[1984]). Festa no Pedaço: cultura popular e lazer na cidade. São Paulo: Hucitec.

Monteiro, S. (2011). O marco conceitual da vulnerabilidade social. Sociedade em Debate, 17(2), pp. 29-40.

Muniagurria, L. (2006). "Ganhar olhar": estudo antropológico de ações de mediação em exposições de artes visuais. (Dissertação de Mestrado em Antropologia Social). Porto Alegre: Universidade Federal do Rio Grande do Sul.

\section{Outras Referências}

Ibram - Portal do Instituto brasileiro de museus. http://www.museus.gov.br (Acesso em 4 de maio 2018).

MuseusBR - Rede Nacional De Identificação De Museus. Base de dados. http://museus.cultura.gov.br/ (Acesso em 10 de março 2018).

Prefeitura da Cidade do Rio de Janeiro. Bairros Cariocas. Armazém de dados. http://portalgeo.rio.rj.gov.br/bairroscariocas/index_bairro.htm (Acesso em 7 de março 2018). 